\title{
Study of anaemia amongst OPD patients visiting a private medical college in Lucknow, Uttar Pradesh
}

\author{
Smriti Rastogi ${ }^{1}$, Shah Mohd. Abbas Waseem ${ }^{2, *}$, Rubeena Bano ${ }^{3}$ \\ ${ }^{\mathbf{1} R e s e a r c h ~ S c h o l a r, ~ D e p t . ~ o f ~ P h y s i o l o g y, ~ K i n g ~ G e o r g e ' s ~ M e d i c a l ~ U n i v e r s i t y, ~ L u c k n o w, ~ U t t a r ~ P r a d e s h, ~}{ }^{2}$ Associate Professor, \\ ${ }^{3}$ Professor, Dept. of Physiology, IIMS\&R, Integral University, Lucknow, Uttar Pradesh, India
}

*Corresponding Author: Shah Mohammad Abbas Waseem

Email: abbas14waseem5@gmail.com

Received: $13^{\text {th }}$ July, 2018

Accepted: $15^{\text {th }}$ October, 2018

\begin{abstract}
Introduction: Anaemia is multi factorial with widespread negative consequences on health. It is more common in developing countries. It has a negative influence on the social and economic development of country.

Materials and Methods: This study included 211 anaemic and 174 non anaemic subjects. Age, gender, socio economic status, dietary habits and education was enquired about and haematological parameters were analysed. Data was analysed using appropriate tests.

Results: $54.8 \%$ patients attending OPD's were found to be anaemic. It was higher in females (65\%) than males $(41.2 \%)$. As per WHO classification mild, moderate and severe anaemia was present in $54.98 \%, 37.91 \%$ and $7.11 \%$ subjects respectively. $63.99 \%$ anaemic subjects belonged to upper to middle class and $36.01 \%$ belonged to lower middle and lower class. Anaemia was higher in subjects belonging to middle to lower classes and those belonging to low education class like high school to illiterate class. Not much difference was found on the basis of dietary preferences. However the percentage of anaemic subjects with mixed dietary habits was slightly higher.

Conclusion: On the basis of study it may be concluded that amongst OPD patient's gender, socioeconomic status and education play role directly or indirectly in anaemia.
\end{abstract}

Keywords: Anaemia, Socio economic, Education, Diet, Gender, OPD's.

\section{Introduction}

Anaemia characterized by low Haemoglobin concentration is a major public health problem affecting $2 \%$ of population globally and is more common in developing countries. ${ }^{1}$ It affects people from low, middle and high income countries. It results in poor pregnancy outcome, cardiovascular diseases, cognitive disabilities and decline in the work capacity which is proportional to severity and maternal and fetal morbidity and mortality. ${ }^{2-6}$ It is estimated that in developing countries, $42 \%$ of children below the age of 5 years and $53 \%$ of children of 5-14 years age are anaemic. ${ }^{7}$ As per the report of NFHS-3 (2005-2006), $70 \%$ of children between ages of 6-59 months are anaemic in India. Out of these $70 \%$ majority are suffering from moderate anaemia i.e. $40 \%$. The probability of anaemia in children is found to increase if the mother herself suffers from anaemia. 55\% of female population in India were found to be suffering from anaemia. $25 \%$ of Indian males were found to be anaemic in the survey. ${ }^{8}$ Common causes of anaemia are inflammation, chronic disease, iron deficiency, maturation defects, hemolysis, haemorrhage, tumors and bone marrow defects. ${ }^{9-13}$ Dietary factors play an important role in anaemia and are more critical in low to middle income countries. The dietary preference does influence the bioavailability of nutrients. Lack of balanced diet may expose an individual to anaemia. ${ }^{14}$

Social determinants of health also play an important role in the development of anaemia. These determinants include the conditions in which the people are born, living, working and age. These also include the factors which affects the living conditions. ${ }^{15}$ Studies have shown that with increase in house hold income the trend of anaemia decreases. ${ }^{16}$ Low socioeconomic status is an important risk factor for developing anaemia. ${ }^{17}$ Studies have also shown association between nutrition, education and family income with anaemia. Education influences not only outcome of anaemia but also influences the attitude about anaemia. Studies have shown that educated parents are more likely to be aware about the causes and consequences of nutritional anaemia. ${ }^{18}$ It has been found that women who have children and women who are working have more awareness about the nutritional anaemia and subsequently are found to be more health conscious. ${ }^{19,20}$ Socio-demographic factors like education, type of family, parity, spacing and different trimesters significantly determines maternal anaemia. ${ }^{21}$

Thus need of the hour is to work on programs which look beyond the traditional approach of evaluating the effectiveness of program's in terms of increase in life expectancy or disability adjusted life years. ${ }^{22}$ Since anaemia is multi factorial and also includes socio demographic factors, thus it is important that holistic and inclusive approach be followed.

Justification of the Study: Results of a recent study show high prevalence of anaemia in Lucknow. Prevalence of anaemia is an indicator of poor nutrition and health. It has potential to negatively affect the 
social and economic development of Nation. ${ }^{23}$ Keeping in view the public health importance of anaemia, its consequences and long term health affects the present study was undertaken. The objective was to analyse the burden of anaemia in subjects belonging to various socioeconomic and education class.

\section{Materials and Methods}

The present study was cross sectional study conducted between January to June 2017 in Department of Physiology and the various OPD'S of Integral Institute of Medical Sciences and Research, Lucknow. 385 subjects were enrolled from various OPD'S of Hospital after following inclusion (18-60 years of age, those attending OPD and willing to participate in the study) and exclusion criterion (anaemic patients already taking medication, not giving consent, suffering from chronic diseases, less than 18 years of age and greater than 60 years of age and pregnant females). Blood Samples were collected under aseptic condition from the various OPD's by using a disposal syringe in an EDTA vial. The samples were analysed using Automated Analyser (Beckman Coulter) in the central pathology lab of IIMS\&R, Lucknow. The study was approved by Institutional Research and Ethical Committees.

\section{Statistical Analysis}

The data was analysed using Statistical Package for Social Science software (21.0). Statistical tests Chi Square and unpaired test were used to analyse the data. $\mathrm{P}$ value $<0.05$ was taken as significant.

\section{Results and Observations}

Table 1: Haematological parameters in anaemic and non anaemic subjects ${ }^{\dagger}$

\begin{tabular}{|l|c|c|c|}
\hline Characterstic & Anaemic(n=211) & Non Anaemic(n=174) & P value(t test) \\
\hline Age & $34.32 \pm 12.65$ & $32.72 \pm 12.63$ & 0.217 \\
\hline Haematological & & & \\
Parameters & & & \\
$\mathrm{Hb}$ & $10.64 \pm 1.61$ & $13.86 \pm 1.49$ & $<0.001$ \\
MCV & $77.51 \pm 3.82$ & $89.47 \pm 4.70$ & $<0.001$ \\
MCH & $26.00 \pm 1.23$ & $27.76 \pm 1.30$ & $<0.001$ \\
MCHC & $31.40 \pm 2.16$ & $32.35 \pm 2.03$ & $<0.001$ \\
\hline
\end{tabular}

( $†$ The mean age of anaemic group was $34.32 \pm 12.65$ years and that of non anaemic group was $32.72 \pm 12.63$ years. The difference was statistically non significant at $\mathrm{p}=0.217$. There were statistically significant differences between the anaemic and non anaemic group when hematological parameters namely $\mathrm{Hb}, \mathrm{MCV}, \mathrm{MCH}$ and $\mathrm{MCHC}$ were compared).

Table 2: Differences between anaemic and non-anaemic subjects

\begin{tabular}{|l|c|c|c|c|c|}
\hline \multicolumn{1}{|c|}{ Parameter } & \multicolumn{2}{|c|}{ Anaemic } & \multicolumn{2}{c|}{ Non Anaemic } & P value(Chi \\
Square test)
\end{tabular}


(*Out of total 385 subjects anaemia was present in 211 i.e. $54.8 \%$ and absent in 174 i.e.45.2\%. 68/165(41.2\%) males and 143/220(55\%) females were anaemic. Similarly, 97/165(58.85) males and 77/220(35\%) females were non anaemic. Out of total 211 anaemic patients 68/211(32.23\%) were males and 143/211(67.77\%) were females. Similarly, out of total 174 non anaemic patients, $97(55.75 \%)$ and $77(44.25 \%)$ were males and females respectively).

Table 3: Haematological parameters as per severity of anaemia

\begin{tabular}{|l|c|c|c|c|c|}
\hline Haematological & Non Anaemic & \multicolumn{3}{|c|}{ Anaemic(n=211) } & \\
\cline { 3 - 5 } & $(\mathbf{n = 1 7 4})$ & Mild(n=116) & Moderate(n=80) & Severe(N=15) & P value \\
\hline $\mathrm{Hb}$ & $13.86 \pm 1.49$ & $11.53 \pm 0.77$ & $9.86 \pm 1.13$ & $6.82 \pm 1.01$ & $<0.001$ \\
$\mathrm{MCV}$ & $89.47 \pm 4.70$ & $79.27 \pm 2.70$ & $75.30 \pm 1.45$ & $71.52 \pm 2.06$ & $<0.001$ \\
$\mathrm{MCH}$ & $27.76 \pm 1.30$ & $26.54 \pm 0.83$ & $25.44 \pm 1.00$ & $24.17 \pm 1.12$ & $<0.001$ \\
$\mathrm{MCHC}$ & $32.35 \pm 2.03$ & $31.71 \pm 1.83$ & $31.53 \pm 2.13$ & $31.11 \pm 2.21$ & $<0.001$ \\
\hline
\end{tabular}

${ }^{(}$Amongst anaemic group 116/211(54.98\%) had mild anaemia, whereas 80/211(37.91\%) and 15/211(7.11\%) subjects had moderate and severe anaemia respectively. The difference between hematological parameters between non anaemic and anaemic group as per grades was found to be statistically significant. Out of total 385 subjects mild, moderate and severe anaemia was present in 116(30.13\%), 80(20.78\%) and 15 (3.90\%) subjects respectively).

Table 4: Distribution as per grades of anaemia

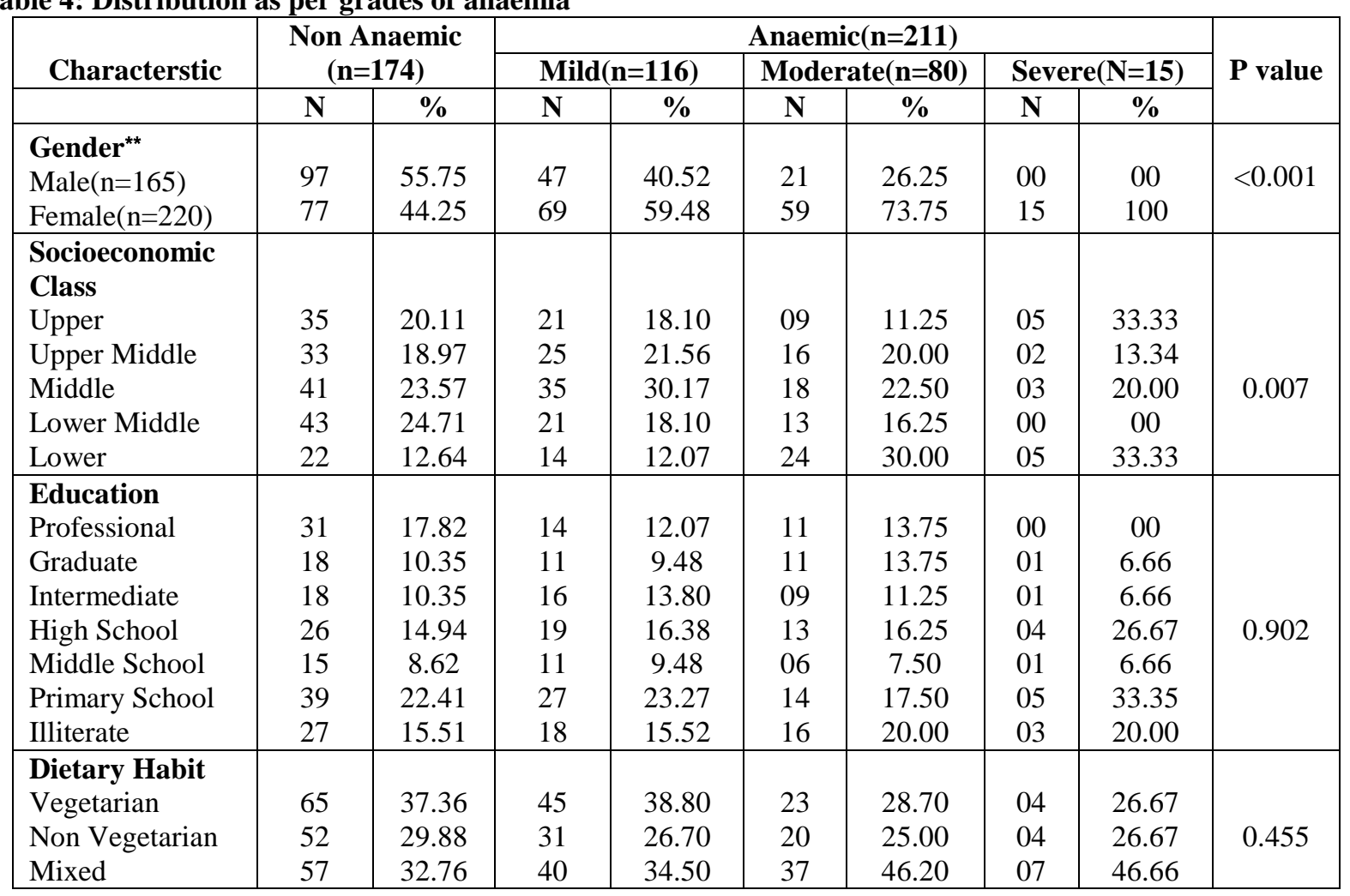

$\left[{ }^{* *}\right.$ Out of total 165 male subjects, mild and moderate anaemia was present in 47(28.50\%) and 21(12.73\%) subjects respectively. Similarly, out of total 220 females mild, moderate and severe anaemia was present in 69(31.36\%), $59(26.82 \%)$ and $15(6.82 \%)$ females respectively. Out of total 116 mild anaemic subjects $47(40.52 \%)$ were males and $69(59.48 \%)$ were females respectively. Similarly, 21/80(26.25\%) males and 59/80(73.75\%) females were having moderate anaemia. All the patients with severe anaemia were found to be females i.e. $15 / 15(100 \%)]$.

\section{Discussion}

Anaemia is a major public health problem in India. ${ }^{24}$ As per WHO anaemia particularly iron deficiency anaemia "reduces the work capacity of individuals and entire populations, bringing serious economic consequences and obstacles to national development". ${ }^{25}$
In present study 211 out of 385 subjects were found to be anaemic i.e. 54.8\%. The mean age of anaemic subjects was higher than non anaemic subjects. Mild, moderate and severe anaemia was found in $54.98 \%, 37.91 \%$ and $7.11 \%$ subjects respectively. Among 220 female subjects anaemia was found in 65\% and among 165 male subjects anaemia was found in $41.2 \%$. Singh BP et al, in their study concluded that 
high prevalence of anaemia among females of Uttar Pradesh is a burden both at personal and familial level. It is bound to have negative impact on economic and social productivity. Further they observed that diet may play a role in females (belonging to overweight and high income category) suffering from moderate to severe anaemia. ${ }^{26}$ The results of study are similar to study done by Ismail I M et al who found prevalence of anaemia to be $51 \%$. In their study $33.3 \%$ males and $64.6 \%$ females were found to be anaemic. ${ }^{27}$

Anaemia was found in $53.2 \%$ of males out of which $34.3 \%$ were having mild anaemia while $17.7 \%$ and $1.2 \%$ were having moderate and severe anaemia; in females $70.1 \%$ were anaemic, which included $48.7 \%$ mild, $19.9 \%$ moderate and $1.5 \%$ severe anaemia cases in a study done by Verma $\mathrm{P}$ et al. $^{23}$ In present study mild, moderate and severe anaemia was present in $31.36 \%, 26.82 \%$ and $6.82 \%$ females respectively. Ghosh S analysed the data of NFHS 3 and found that mild, moderate and severe anaemia was present in $47.9 \%, 16.1 \%$ and $1.6 \%$ female subjects respectively. ${ }^{28}$ The results can be explained on the basis that sample size was small and may not be representative of overall population and also because of the non inclusion of pregnant females. $28.48 \%$ and $12.73 \%$ males were found to have mild and moderate anaemia respectively.

Increase requirements and low intake of dietary iron and absorption, parasitic infections, hereditary haemoglobinopathies, menstrual; loss, adolescent pregnancies, increase in trend of consumption of processed and packed food rich in salt and low in nutrients, low intake of green leafy vegetables and fruits and increase in socio economic gaps may be responsible for high prevalence of anaemia amongst females. ${ }^{29,30}$

The mean age of anaemic group was found to be higher than non anaemic group in present study. The results are similar to a study done by Uria GA et al, who found that risk of anaemia increases with advancing age. ${ }^{31}$ In males with advancing age there is decrease in the levels of androgens which contributes to reduction in erythroid mass and may explain the reason for anaemia with advancing age in males. ${ }^{32}$ The risk of nutritional deficiencies increases with advancing age in females. ${ }^{33}$ With age there is increase in pro inflammatory cytokines and decrease in proliferative and regenerative capacity of bone marrow stem cells. ${ }^{34}$ The mean age of females was found to be less than that of males. Pregnant females were excluded from the study. Increase in blood volume, increase demands for growth and development, parasitic infections, H. Pylori infection, micronutrients and nutritional deficiencies and hemoglobinopathies results in anaemia associated with pregnancy. ${ }^{35,36}$

In non pregnant females nutritional deficiencies and non nutritional causes like parasitic infections, helminthic infestations, sickle cell anaemia, chronic and inflammatory diseases are main causes of anaemia. ${ }^{37}$
As per the WHO grading of anaemia it was found that mild, moderate and severe anaemia was present in $31.36 \%, 26.82 \%$ and $6.82 \%$ females respectively. On the other hand $28.50 \%$ and $12.73 \%$ males were found to have mild and moderate anaemia respectively. $\mathrm{P}$ value was significant at $<0.001$. The results are similar to a study done by Agarwalla R et al who found that mild and moderate anaemia is more prevalent in females as compared to males. ${ }^{38}$

High prevalence of anaemia in females may reflect social and biological vulnerability both within society and the household. ${ }^{39}$ Anaemia is one of the important health problems among women of 18-45 years of age in the world and especially in developing countries and warrants immediate attention. ${ }^{40}$

Difference was significant between males and females when hematological parameters namely $\mathrm{Hb}$, $\mathrm{MCV}, \mathrm{MCH}$ and $\mathrm{MCHC}$ were compared $(\mathrm{p}<0.001)$. Possible explanation can be influence of testosterone in males and blood loss in females respectively. ${ }^{41,42}$ Androgen exerts stimulatory effect on bone marrow and also stimulates production of erythropoietin from kidney which enhances red cell mass whereas female sex hormone oestrogen has inhibitory effect on bone marrow. 43,44

$\mathrm{Hb}, \mathrm{MCV}, \mathrm{MCH}$ and $\mathrm{MCHC}$ values were found to be lower in Indian Male sand Females as compared to American Whites in a study done by Pasupul DK et al. ${ }^{45}$ In our study values are lower than Indian males and Females. The possible reason could be the effect of anaemia on Haematological Parameters. MCV is an indicator of size of RBC. High or low MCV is indicative of anaemia depending upon the cause and pathophysiology. Amount of $\mathrm{Hb}$ in $\mathrm{RBC}$ is measured by $\mathrm{MCH}$, thus decrease in $\mathrm{MCH}$ levels indicate anaemia. MCHC on the other hand measures average concentration of $\mathrm{Hb}$ in each cell. Decrease in MCV, $\mathrm{MCH}$ and $\mathrm{MCHC}$ is indicative of microcytic, hypochromic anaemia usually due to iron deficiency. Increase $\mathrm{MCV}$ and variable $\mathrm{MCH}$ and $\mathrm{MCHC}$ is indicative of folic and vitamin B12 deficiency. ${ }^{46}$

In present study $62.65 \%$ non anaemic and $63.99 \%$ anaemic subjects belonged to upper to middle class. $37.35 \%$ non anaemic and $36.01 \%$ anaemic subjects belonged to lower middle and lower class. Overall $60.34 \%, 68.75 \%$ and $53.33 \%$ of subjects with mild, moderate and severe anaemia belonged to middle to lower classes. Similarly, in mild anaemic group $41 / 116(35.35 \%)$ and $75 / 116(64.65 \%)$ subjects belonged to professional to intermediate and high school to illiterate education class respectively. In moderate anaemic group $38.75 \%$ i.e. $31 / 80$ subjects belonged to professional to intermediate education class whereas $49 / 80$ i.e. $61.25 \%$ subjects were from high school to illiterate education class. In severe anaemic group majority of subjects i.e. 13/15(86.68\%) were from high school to illiterate education class and rest i.e. $2 / 15(13.32 \%)$ belonged to professional to graduate 
education class. Zaytoun SS et al found that those with low social class were at higher risk for anaemia than other classes. ${ }^{47}$ Lee $\mathrm{JO}$ et al found that apart from gender, age and physiological state, low socio economic state, underweight and iron and vitamin $\mathrm{C}$ deficient diet is a risk factor for iron deficiency anaemia. ${ }^{48}$ Iron deficiency is most common among groups of low socioeconomic status. ${ }^{49}$ A study done by Bharati $\mathrm{P}$ et al, found high prevalence of anaemia in girls belonging to illiterate houses and those with low standards of living. More married women were found to be anaemic. ${ }^{50}$

Higher anaemia prevalence in rural regions has been attributed to disparities in health service provision and access, disease risk, fertility preferences, and genetic conditions such as sickle cell anaemia. ${ }^{51}$ The present study was under taken in a medical college which is remote in location and caters mainly to rural population thus the above factor can possibly explain the results. Females belonging to low income families or class are particularly vulnerable to anaemia specifically iron deficiency anaemia. Low income levels can cause poor nutrition and improper diet which in turn can put women at risk of suffering iron deficiency anaemia. ${ }^{52}$

Kaur $\mathrm{S}$ et al attributed the high prevalence of anaemia among adolescent girls to low socioeconomic, low iron intake, vegetarian diet, history of worm infestation and history of excessive menstrual bleeding. Age, BMI and education were found to be less contributory factors. ${ }^{53}$ Significant association of anaemia has been found with educational status, birth order and awareness regarding anaemia. ${ }^{54}$ Association of low socio economic status, low education and BMI was associated with high prevalence of anaemia in a study done in rural population of North India. ${ }^{55}$ Low socioeconomic status is associated with low intake of micronutrients. Direct link between low socio economic status and iron deficiency has been reported in several studies. Another associated aspect is low calorie intake in this class. ${ }^{56}$ Low socio economic status and poor dietary habits together or alone can produce anaemia and also exacerbate the associated symptoms.

Sharma $\mathrm{P}$ et al in their study found that risk of anaemia was more in pregnant women belonging to low socio economic class and with low education. ${ }^{57}$ Improvements in socio economic factors, education and living conditions can contribute to reduce the prevalence of iron deficiency anaemia. ${ }^{58}$ Although in the present study we did not included pregnant women but still it is clear that the socio economic status and literacy are the major determinants and contributory/ risk factors in anaemia and must be given emphasis if the growing problem/burden of anaemia has to be dealt effectively. In present study percentage of vegetarian, non vegetarian and mixed dietary habit subjects in non anaemic group were found to be $37.36 \%, 29.88 \%$ and $32.76 \%$ respectively. In anaemic group $35.07 \%$ subjects were vegetarian, $26.07 \%$ were non vegetarian and $38.86 \%$ subjects were of mixed dietary habit. Generally, education, culture and family practices influence the dietary habits. Dietary preferences may also change over period of time. Dietary patterns are influenced by older siblings (not in a positive manner) and the education of their grandparents as well as their parents. Children of less-educated parents have less healthy dietary patterns. ${ }^{56}$

There are contrasting results as far as influence of dietary preferences and habits on anaemia are concerned. Sharma SV et al found low haemoglobin level in vegetarian obese women than the omnivores women and suggested that the macronutrient in omnivores is higher than in vegetarian and control group. ${ }^{59}$ The study by Cheema HK et al revealed that $83.3 \%$ anaemic women were following vegetarian pattern of diet where as $50 \%$ and $28.3 \%$ anaemic pregnant women were following non vegetarian (diet based on daily or several times weekly consumption of meat/ eggs/fish /chicken) and mixed pattern dietary pattern respectively. ${ }^{60}$

Quantity of iron in vegetarian diet may be same or even higher than mixed non vegetarian diet. Much research is required on physiological impact of low ferritin levels in vegetarians. However by consuming diet rich in vitamin $\mathrm{C}$ and organic acids, vegetarians may reduce the risk of low levels of iron.$^{61}$ As of now, research has shown that vitamin B12 is poor in plant food sources. Thus, vegetarians need to consume fortified foods and dietary supplements to prevent the deficiency of vitamin B12.62 Iron levels can be improved by consuming diet rich in green leafy vegetables, yellow fruits, fortified food and use of iron utensils for cooking. Absorption of Iron can be improved by including citrus fruits. ${ }^{63}$

\section{Conclusions}

Anaemia is more common in females than males. Advancing age also makes the subject prone to anaemia by causing and hormonal imbalance in body apart from other factors. Low socio economic status and low education are also risk factors as they directly or indirectly influence the awareness about health and hygiene and make the subject more vulnerable to risk factors. Dietary preferences also influence the prevalence of anaemia.

\section{Limitations}

Parameters like serum iron, ferritin were not measured in the present study. Aetiology and morphological classifications, interplay of environmental and various risk factors was not analysed. Pregnant females and children were not included in present study. 
Acknowledgement: Authors are thankful to participants (and wish them a speedy recovery and good health) and supporting study.

\section{Conflict of Interest: None declared.}

\section{References}

1. Global anaemia prevalence and number of individuals affected. World Health

OrganizationWebsite.http://www.who.int/vmnis/anaemia/ prevalence/summary/anaem ia_data_status_t2/en/.

2. Sen A and Kanani SJ. Deleterious Functional Impact of Anaemia on Young Adolescent School Girls. Indian Pediatrics. 2006;43:219-226.

3. Scholl TO, Hediger ML. Anaemia and Iron deficieny Anaemia: compilation of data on pregnancy outcome. American Journal of clinical Nutrition. 1994;8:492S $500 \mathrm{~S}$.

4. Gupta SK, Agarwal SS, Kaushal R, Jain A, Gupta VK and Khare N. Prevalence of Anaemia among rural population living in and around of rural health and training center, Ratua Village of Madhya Pradesh. Muller Journal of Medical Sciences and Research. 2014;5(1):1518.

5. Royston E. The prevalence of nutritional anaemia in women in developing countries: A critical review of available information. World Health Stat Q. 1982;35:5291.

6. Makaron E.J, Taher T.A, Conrad. E.M. Anaemia: Practice Essentials, Pathophysiology, Etiology. 2016.

7. Vendt N, Grunberg H, Leedo S, Tillmann V \& Talvik T. Prevalence and causes of iron deficiency Anaemia in infants aged 9 to 12 months in Estonia. MEDICINA (Kaunas) 2007;43(12):947-52.

8. International Institute for Population Sciences (IIPS) and Macro International. 2007. National Family Health Survey (NFHS-3), 2005-06, India: Key Findings. Mumbai: IIPS.

9. Rabindran, Gedam DS. Anaemia: Increasing prevalence in general population: why? Int J Med Res Rev. 2015;3(7):673-674. doi: 10.17511/ijmrr.2015.i7.144.

10. Mehdi U, Toto RD. Anaemia, Diabetes, and Chronic Kidney Disease. Diabetes Care. 2009;32(7):1320-1326.

11. Kaitha S, Bashir M, Ali T. Iron deficiency anaemia in inflammatory bowel disease. World J Gastrointest Pathophysiol. 2015;6(3):62-72.

12. Hillman RS, Finch CA. Red Cell Manual. 7th ed. Philadelphia, PA: FA Davis; 1996:1-38.

13. Kayode O. Osungbade and Adeolu O. Oladunjoye (2012). Anaemia in Developing Countries: Burden and Prospects of Prevention and Control, Anaemia, Dr. Donald Silverberg (Ed.), ISBN: 978-953-51-0138-3, In Tech, Available from: http://www.intechopen.

14. Balarajan Y, Ramakrishnan U, Ozaltin E, Shankar AH, Subramanian SV. Anaemia in low-income and middleincome countries. 2011;378:2123-35. doi:10.1016/S01406736(10)62304-5

15. Available online at www.who.int/social_determinants/sdh_definition/en/2017

16. Kim JY, Shin S, Han K, Lee KC, Kim JH, Choi YS, Kim DH, Nam GE, Yeo HD, Lee HG and Ko BJ. Relationship between socioeconomic status and anaemia prevalence in adolescent girls based on the fourth and fifth Korea National Health and Nutrition Examination Surveys. Eur J Clin Nutr. 2014;68(2):253-8. doi: 10.1038/ejen.2013.241.
17. Dey S, Goswami S and Goswami M. Prevalence of anaemia in women of reproductive age in Meghalaya: A logistic regression analysis. Turk J Med Sci. 2010;40(5):783-789.

18. Mehta K. Prevalence of Nutritional Anaemia among College Students and its Correlation with their Body Mass Index. International Journal of Science and Research. 2015;4(3):1882-1886.

19. Charlotte Adams, Alice Costello, Sarah Flynn. Iron Deficiency Anaemia In Ecuador: Does Education Matter? Cited 2009 Available from http://www.bloodmed.com/home/Newsitemattachement_ 1147.pdf.

20. Hussain T and Shu LY. Awareness of Iron Deficiency Anaemia among women of Reproductive age in Hubei Province, China. Asian Journal of Medical Sciences. 2010;1:12-13.

21. Nwizu EN, IliyasuZ,Ibrahim SA and Galadanci HS. Socio-Demographic and Maternal Factors in Anaemia in Pregnancy at Booking in Kano, Northern Nigeria. African Journal of Reproductive Health December. 2011;15(4):33-41.

22. Zimmermann B. Michael, Badham J. The Guidebook Nutritional Anaemia, ed: Klaus Kraemer: Sight and life: Switzerland.

23. Pratima V, Shraddha S, Ashutosh K, Archna G and Ahilesh K. Prevalence of Anaemia in adults with respect to Socio-Demographic status, Blood groups and religion in North Indian population. Int J Biol Med Res. 2012;3(4):2441-2447.

24. Anand T, Rahi M, Sharma P and Ingle GK. Issues in prevention of iron deficiency anaemia in India. Nutrition. 2014;30(7-8):764-70. doi: 10.1016/j.nut.2013.11.022.

25. http://smartinvestor.business-standard.com/market/story421363-storydet anaemia_is_the_biggest_cause_of_disability_in_India_w orst_in_BRICS.htm.

26. Singh BP, Maheshwari S and Gupta PK. Anaemia in Married Females of Uttar Pradesh and Its relation to Body Mass Index: Application of Poisson Regression. Journal of Data Sciences. 2017;15:267-274.

27. Ismail IM, Kahkashan A, Antony A and Sobhit VK. Role of socio-demographic and cultural factors on anaemia in a tribal population of North Kerala, India. Int J Community Med Public Health. 2016;3(5):1183-1188.

28. Ghosh S. Exploring socioeconomic vulnerability of anaemia among women in eastern Indian states. Journal of Biosocial Science. 2009;41(6):763-787.

29. Balarajan YS, Fawzi WW and Subramaniam SV. Changing patterns of social inequalities in anaemia among women in India: cross-sectional study using nationally representative data. BMJ Open. 2013;3:e002233. doi: 10.1136/bmjopen-2012002233.

30. Jadhav BN. A critical review on iron deficiency anaemia in female population of developing India. International Journal of Fauna and Biological Studies. 2016;3(5):116119.

31. Uria GA, Naik PK, Midde M, Yalla PS, and Pakam R. Prevalence and Severity of Anaemia Stratified by Age and Gender in Rural India. Anaemia. 2014; http://dx.doi.org/10.1155/2014/176182.

32. Roy CN, Snyder PJ, Stephens-Shields AJ, Artz AS, Bhasin S, Cohen HJ et al. Association of Testosterone Levels With Anemia in Older MenA Controlled Clinical Trial. JAMA Intern Med. 2017;177(4):480-490. doi:10.1001/jamainternmed.2016.9540

33. Chernoff R. Micronutrient requirements in older women. Am J of Clin Nutr. 2005;81(5):1240S-1245S. 
34. Kovtonyuk LV, Fritsch K, Feng X, Manz MG and Takizawa H. Inflamm-Aging of Hematopoiesis, Hematopoietic Stem Cells, and the Bone Marrow Microenvironment. Front Immunol. 2016;7:502. doi: 10.3389/fimmu.2016.00502.

35. Yaghoobi H, Zolfizadeh F, Asadollahi Z, Vazirinejad R and Rezaeian M. Prevalence of iron deficiency anaemia and some related factors among pregnant women referred to healthcare centers in Bandar Lengeh, Iran, in 2015. JOHE. 2015;4(2):92-100.

36. Rahmati S, Delpishesh A, Parizad N and Sayhmiri K. Maternal Anaemia and Pregnancy outcomes: a Systematic Review and Meta-Analysis. Int $J$ of Pediatr. 2016;4(8):3323-3342.

37. Pande D, Saroshe S, Pandey D, Dixit S, Shukla H and Tiwari S. Estimation of prevalence of anaemia using WHO haemoglobin color scale among non pregnant females of urban slum. Global Journal of Medicine and Public Health. 2014;3(3):1-7.

38. Agarwalla R, Saikia AM, Parashar M, Pathak R, Islam F. Assessment of prevalence of anaemia in and its correlates among community-dwelling elderly of Assam, India: A cross-sectional study. Int J Nutr Pharmacol Neurol Dis. 2016;6:23-7.

39. Maiti S, Ali KM, Ghosh A, Ghosh K, Ghosh D and Paul S. Prevalence of Anaemia among Rural Women Population of Paschim Medinipur, West Bengal, India. Nepal Journal of Medical Sciences. 2013;2(1):9-12.

40. Taha, A., Azhar, S., Lone, T., Murtaza, G., Khan, S. A., Mumtaz, A. Hussain, I. Iron Deficiency Anaemia in Reproductive Age Women Attending Obstetrics and Gynecology Outpatient of University Health Centre in Al-Ahsa, Saudi Arabia. African Journal of Traditional, Complementary, and Alternative Medicines. 2014;11(2):339-342.

41. Rushton DH and Barth JH. What is the evidence for gender differences in ferritin and haemoglobin? Critical Reviews in Oncology/Hematology.2010; 1-9. doi:10.1016/j.critrevonc.2009.03.010.

42. Woo J, Arumanayagam M, Ho SC and Swaminathan R. Hematological indices and the prevalence of anaemia in an elderly Chinese population. Pathology. 1989;21(1):3134.

43. Jelkmann W. Regulation of erythropoietin production. $J$ Physiol. 2011;598:1252-8.

44. Shahani S, Braga-Basaria M, Maggio M, Basaria S. Androgens and erythropoiesis: past and present. $J$ Endocrinol Invest. 2009;32:704-16.

45. Pasupula DK, Reddy PS. When is a South Indian Really Anaemic? Indian Journal of Clinical Biochemistry. 2014;29(4):479-484. doi:10.1007/s12291-013-0386-0.

46. http://my.ilstu.edu/ ddwilso2/nur475/Anaemia_Notes.ht $\mathrm{m}$.

47. Zaytoun SS and Khan EA. Sociodemographic risk factors of iron deficiency anaemia in young adult males of upper Egypt. KMUJ. 2016;8(3):123-127.

48. Lee J-O, Lee JH, Ahn S. Prevalence and Risk Factors for Iron Deficiency Anaemia in the Korean Population: Results of the Fifth Korea National Health and Nutrition Examination Survey. Journal of Korean Medical Science. 2014;29(2):224229. doi:10.3346/jkms.2014.29.2.224.

49. Iron Deficiency Anaemia Assessment, Prevention, and Control A guide for programme managers WHO/NHD/01.3Distribution: General English only United Nations Children's Fund United Nations University World Health. Available online at WHO_NHD_01.3 - Documents. documents.tips > Documents.
50. Bharati P, Shome S, Chakrabarty S, Bharati S and Pal M. Burden of anaemia and its socioeconomic determinants among adolescent girls in India. Food and Nutrition Bulletin. 2009;30(3):217-226.

51. Adamu AL, Crampin A, Kayuni N, Amberbir A, Koole O, Phiri A, Nyirenda M and Fine P. Prevalence and risk factors for anaemia severity and type in Malawian men and women: urban and rural differences. Population Health Metrics. 2017;15(12). DOI: 10.1186/s12963-0170128-2.

52. Aziz-Karim S, Khursheed M, Rizvi JH. Anaemia in pregancy-a study of 709 women in Karachi. Tropical Doctor. 1990;20:184-185.

53. Kaur S, Deshmukh P. R, Garg B. S. Epidemiological correlates of nutritional anaemia in adolescent girls in rural Wardha. IJCM. 2006;31(4):255-258.

54. Rawat C. M. S, Garg S. K, Singh J. V. Socio demographic correlates of anaemia among adolescent girls in rural area of Meerut. IJCM. 2001;26(4):173-175.

55. Malhotra P, Kumari S, Kumar R and Varma S. Prevalence of anaemia in adult rural population of north India. J Assoc Physicians India. 2004;52:18-20.

56. Darmon N and Drewnowski. Does Social Class Predict Diet Quality. Am J Clin Nutr. 2008;87(5):1107-1117.

57. Sharma P, Mehta S and Nagar R. Prevalence of anaemia and socio-demographic factors associated with anaemia among pregnant women attending antenatal Hospital in Jaipur City, India. Journal of Pharmacy and Biological Sciences. 2013;6(3):1-5.

58. Tembhare A, Shelke S, Shivekumar PV and Tayade S. Socio-demographic determinants associated with iron deficiency anaemia in pregnancy in rural population of central India. International Journal of Biomedical and Advance Research. 2015;6(12):817-823.

59. Sharma SV, Koonwar S, Atam V, Singh U and Patel ML. Study of hemoglobin in vegetarian and non vegetarian diet in obese women with risk of cardiac problem in Lucknow city. National Journal of Medical Research. 2013;3(2):169-172.

60. Cheema HK, Bajwa Singh Baljit, Kaur Kulbir, Joshi Harshdeep. Prevalence and Possible Risk Factors of Anaemia in Different Trimesters of Pregnancy. International Journal of Contemporary Medical Research. 2016;3(4):1194-1197.

61. Saunders AV, Craig WJ, Baines SK and Posen JS. Iron and vegetarian diets. MJA Open. 2012;1(Suppl 2):11-16. doi: 10.5694/mjao11.11494

62. Osei-Boadi K, Lartey A, Marquis GS and EK Colecraft. Dietary intakes and iron status of vegetarian and nonvegetarian children in selected communities in Accra and Cape Coast, Ghana. African Journal of Food, Agriculture, Nutrition and Development. 2012;12(1):5822-5842.

63. Kumar R. Anaemia: A Common Health Problem, Consequence and Diet Management among Young Children and Pregnant Women. Biological Forum - An International Journal. 2014;6(1):27-32.

How to cite this article: Rastogi S, Waseem S.M.A, Bano R. Study of anaemia amongst OPD patients visiting a private medical college in Lucknow, Uttar Pradesh. Indian J Clin Anat Physiol. 2018;5(4):546-552. 